www.jmscr.igmpublication.org

Impact Factor 5.84

Index Copernicus Value: 83.27

ISSN (e)-2347-176x ISSN (p) 2455-0450

crossref DOI: _https://dx.doi.org/10.18535/jmscr/v5i4.159

\title{
Prospective Randomized Study of Cases of Pelvic Fracture Urethral Distraction Defects (PFUDD) Managed by Initial Suprapubic Urinary Diversion with Delayed Urethroplasty versus Early Realignment with Evaluation of Erectile Dysfunction
}

\section{Authors \\ Dr Parag Sharma (JR3), Prof H.S. Pahwa (Mch Urology) Dr Awanish Kumar (MS) \\ KGMU, Lucknow}

\section{Introduction}

Traumatic injury is a leading national and international health problem. Indeed, trauma is the leading cause of death for people between ages 1 and 37 years. The incidence of urethral injury in men with pelvic fracture varies widely. The results of 2 extensive reviews have shown that the incidence of posterior urethral injury varied from $1.6 \%$ to $25 \%$ (mean $9.9 \%$ ). ${ }^{1,2}$ In the latest studies, it has been estimated to be between $3 \%$ and $25 \%$, and the concomitant injuries of abdominal organs have been also reported in $27 \%$ of them ${ }^{3}$. Posterior pelvic fracture urethral distraction defect (PFUDD) is a challenging urologic problem that may result in complications, such as urinary incontinence and inability to void due to recurrent stricture leading to a lifelong disabling condition. Urethral injuries are overwhelmingly associated with bilateral pubic rami fractures so called straddle fractures and combination of straddle fractures with diastasis of sacroiliac joint has the highest risk of urethral injury.

The best line of treatment of posterior urethral disruption secondary to blunt pelvic trauma remains controversial. Although some investiga- tors recommended early realignment of urethral distraction injuries; these series are often relatively small and follow-up is relatively short $^{[3,4]}$ Although classic reports recommend suprapubic cystostomy placement at the time of trauma with delayed urethral reconstruction 4 to 6 months after trauma through perineal approach, series that advocate primary realignment show a lower rate of urethroplasty as well as the formation of potentially less significant strictures than those treated with suprapubic cystostomy and late repair.

The purpose of this study was to investigate the outcomes of patients undergoing primary realignment for the initial management of acute urethral injuries in Indian scenario. This is an ongoing study and observations made so far are presented here. There are essentially two options for the initial management of traumatic posterior urethral injury; suprapubic catheter (SPC) placement followed by definitive urethral stricture repair after three to six months or primary urethral realignment, immediate or early (1-15 days following injury). 
There is a dearth of literature in the Indian scenario comparing the various techniques of management of distraction injuries of posterior urethra. Hence the purpose of this study is to investigate the outcomes of patients with distraction injuries of the posterior urethra undergoing early alignment (either by rail-roading or endoscopic) compared with initial suprapubic urinary diversion with delayed urethroplasty and evaluate the incidence of erectile dysfunction in both groups at a tertiary level trauma center in Lucknow city.

\section{Material and Methods}

The study included a total of 20 patients admitted to Department of general surgery, KGMU, Lucknow with PFUDD of grade III, IV and V between April 2015 to September 2016. This is a prospective randomized comparative double arm study done on patients of pelvic fracture urethral distraction defects comparing outcomes of primary alignment versus suprapubic cystostomy with delayed urethroplasty and prospective evaluation of erectile dysfunction.

Patient excluded from the study were those who did not give consent, had associated bladder neck injury, PFUDD grade I and II injuries and those who had low levels of serum testosterone.

Patients were randomly assigned to 2 groups. In group 1 patients were managed by initial suprapubic cystotomy followed by urethroplasty at a later setting while the patients in group 2 were managed by early primary realignment (open/endoscopic).

Patients were followed up after 6 weeks and 6 months and the primary outcome measured was rate of stricture formation in both groups which was detected by RGU and uroflowmetry studies done at our institute. Secondary outcome measure was rate of erectile dysfunction and urinary incontinence in both groups at 6weeks and 6 months follow up which was detected by measuring plasma testosterone levels, penile colour doppler and IIEF-5 scoring .Demographic characteristics and baseline biochemical parameters were also compared between the both groups during the follow up.

For uroflowmetry, Qmax of 20ml/s was taken as cut off.IIEF-5 scoring inerpretation

22-25-No erectile dysfunction

17-21-Mild erectile dysfunction

12-16-Mild to moderate erectile dysfunction

8-11-Moderate erectile dysfunction

5-7-Severe erectile dysfunction

Continuous data were summarized as Mean $\pm \mathrm{SE}$ (standard error of the mean) while discrete (categorical) in no. and \%. Continuous groups were compared by independent Student's t test. Continuous groups were also compared by repeated measures two factor analysis of variance (ANOVA) and the significance of mean difference between (inter) the groups was done by Tukey post hoc test after ascertaining normality by Shapiro-Wilk's test and homogeneity of variance by Levene's test. Categorical groups were compared by chi-square $\left(\chi^{2}\right)$ test. The analyses were done according to intent to treatment basis (i.e. only inter group). A twotailed $\mathrm{p}$ value less than $0.05 \quad(\mathrm{p}<0.05)$ was considered statistically significant. Analyses were performed on Statistical Package for Social Sciences (SPSS) software (Windows version 17.0).

\section{Results}

The present prospective randomized study deals with cases of pelvic fracture urethral distraction defects (PFUDDS) managed by early realignment versus initial suprapubic urinary diversion with delayed urethroplasty with evaluation of dysfunction. Total 20 male patients were recruited and randomized equally in to two groups and treated with initial SPC f/b delayed urethroplasty (Group 1) or early realignment (Group 2).The primary outcome measures of the study were Retrograde urethrogram and uroflowmetry. The secondary outcome measures were IIEF-5 scoring, Penile colour Doppler and urinary incontinence. The biochemical parameters were assessed at 2 wk, 6 wk and 6 month post treatment while 
Retrogadeurethrogram, uroflowmetry, IIEF-5 score, RBS, serum testosterone level, penile colour doppler and urinary incontinence were assessed at $6 \mathrm{wk}$ and 6 month post treatment. The objective of the study was to compares the outcome measures over the time between the two groups.

The comparison of demographic (age, mode of injury and general biochemical parameters) and outcome measures between two groups are summarized below:

\section{Demographic characteristics}

The demographic characteristics viz. age and mode of injury of two groups at presentation is summarized in Table 1 and also depicted in Fig. 1 and 2 respectively. The age of Group 1 and Group 2 ranged from 18-40 yrs and 24-40 yrs respectively with mean $( \pm \mathrm{SE}) 28.30 \pm 2.56 \mathrm{yrs}$ and $31.90 \pm 1.78 \mathrm{yrs}$ respectively and median 26 yrs and 32 yrs respectively. The mean age of Group 2 is slightly higher than Group 1 . Comparing the mean age of two groups, $t$ test showed similar age between the two groups $(28.30 \pm 2.56$ vs. $31.90 \pm 1.78, \mathrm{t}=1.16, \mathrm{p}=0.263)$ i.e. did not differ significantly.

Further, in Group 1, the mode of injury of 7 (70.0\%) patients were RTA, 2 (20.0\%) fall from height and $1(10.0 \%)$ miscellaneous while in Group 2, it were $8(80.0 \%), 2(20.0 \%)$ and 0 $(0.0 \%)$ respectively. Comparing the mode of injury frequency (\%) of two groups, $\chi^{2}$ test showed similar mode of injury between the two groups $\left(\chi^{2}=1.07, \mathrm{p}=0.587\right)$ i.e. also not differ significantly. The comparisons concluded that the subjects of two groups were demographically matched and thus comparable and may also not influence the study outcome measures.

\begin{tabular}{|l|c|c|c|c|}
\hline $\begin{array}{l}\text { Demographic } \\
\text { characteristics }\end{array}$ & $\begin{array}{c}\text { Group 1 } \\
(\mathrm{n}=10)(\%)\end{array}$ & $\begin{array}{c}\text { Group 2 } \\
(\mathrm{n}=10)(\%)\end{array}$ & $\begin{array}{c}\mathrm{t} / \chi^{2} \\
\text { value }\end{array}$ & $\begin{array}{c}\mathrm{p} \\
\text { value }\end{array}$ \\
\hline Age (yrs): & $28.30 \pm 2.56$ & $31.90 \pm 1.78$ & 1.16 & 0.263 \\
Mean $\pm \mathrm{SE}$ & $7(70.0)$ & $8(80.0)$ & 1.07 & 0.587 \\
\hline Mode of injury: & $2(20.0)$ & $2(20.0)$ & & \\
RTA & $1(10.0)$ & $0(0.0)$ & & \\
Fall from height & & & \\
Miscellaneous & & & \\
\hline ns $p>0.05$ - as compared to Group 1
\end{tabular}

\section{Age (yrs)}

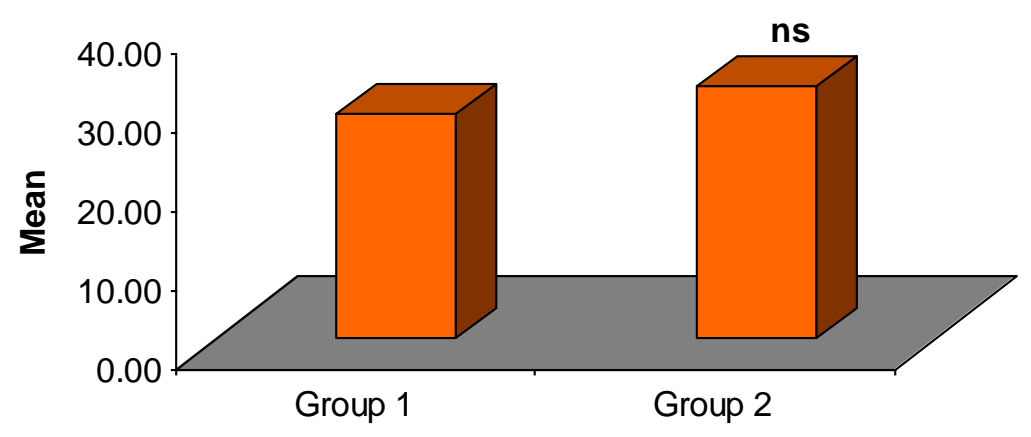

Fig. 1. Mean age of two groups 


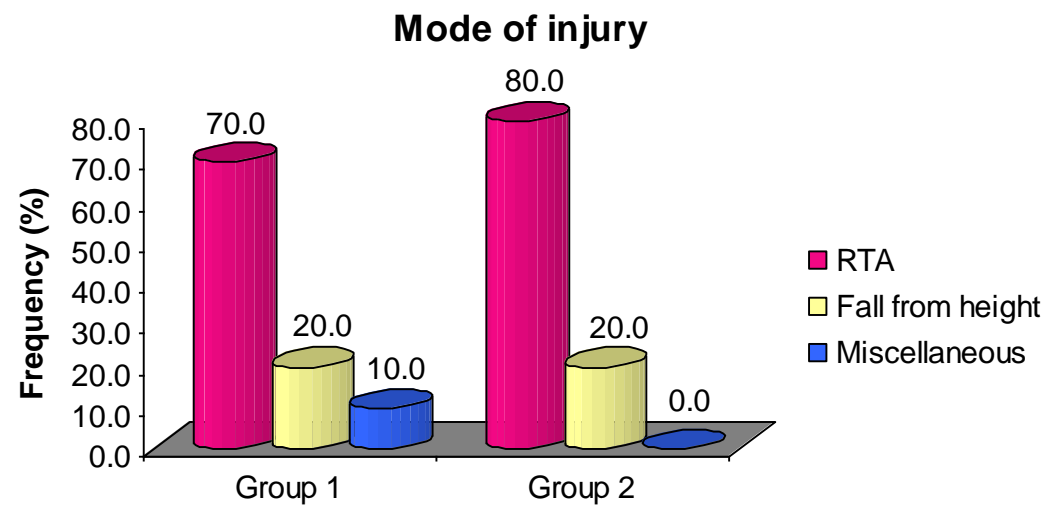

Fig. 2. Distribution of mode of injury of two groups.

\section{Outcome measures}

\section{Primary outcome measure}

\section{Retrograde urethrogram}

The post treatment (6 week and 6 month) retrograde urethrogram distribution (stricture present/absent) of two groups is summarized in Table 3. At week 6, it remains present $100.0 \%$ in Group 1 while 50.0\% in Group 2. At 6 month, it remains present $20.0 \%$ in Group 1 and $10.0 \%$ in Group 2.

For each period, comparing the retrograde urethrogram distribution (stricture present/absent) of two groups, $\chi^{2}$ test showed significant less stricture presence (improvement in retrograde urethrogram) at $6 \mathrm{wk}$ in Group 2 as compared to Group $1\left(100.0 \%\right.$ vs. $\left.50.0 \%, \chi^{2}=6.67, \mathrm{p}=0.010\right)$.
However, at 6 month, the improvement in retrograde urethrogram was similar $(p>0.05)$ between the two groups though the stricture presence was $10.0 \%$ less in Group 2 than Group 1. In group -1 all the 10 patients were operated (bulboprostatic urethral anastomosis) and at 6 months follow up $80 \%$ patients were stricture free while $20 \%$ patients had recurrent stricture formation.

In group 2, 50\% patients who had stricture at 6 weeks were treated with DVIU/Co-axial dilatation. At 6 months follow up 80\% patients were stricture free and voided normally while $20 \%$ had recurrent stricture formation requiring urethroplasty.

Table 3: Post treatment distribution of retrograde urethrogram of two groups over the periods

\begin{tabular}{|l|c|c|c|c|c|}
\hline Period & $\begin{array}{c}\text { Retrograde urethrogram } \\
\text { stricture }\end{array}$ & $\begin{array}{c}\text { Group 1 } \\
(\mathrm{n}=10)(\%)\end{array}$ & $\begin{array}{c}\text { Group 2 } \\
(\mathrm{n}=10)(\%)\end{array}$ & $\begin{array}{c}\chi^{2} \\
\text { value }\end{array}$ & $\begin{array}{c}\mathrm{p} \\
\text { value }\end{array}$ \\
\hline 6 week & Absent & $0(0.0)$ & $5(50.0)$ & 0.67 & 0.010 \\
\cline { 2 - 5 } & Present & $10(100.0)$ & $5(50.0)$ & & \\
\hline 6 month & Absent & $8(80.0)$ & $8(80.0)$ & & \\
\cline { 2 - 5 } & Present & $2(20.0)$ & $2(20.0)$ & & \\
\hline
\end{tabular}

NA: not applicable

\section{Uroflowmetry}

The post treatment (6 week and 6 month) distribution of uroflowmetry (abnormal Qmax $<20 \mathrm{ml} / \mathrm{s} /$ normal flow Qmax $>20 \mathrm{ml} / \mathrm{s}$ ) of two groups is summarized in Table 4. Qmax of
$20 \mathrm{ml} / \mathrm{s}$ was taken as cutoff value. At week 6 , the frequency $(\%)$ of normal flow was significantly higher in Group 2 as compared to Group $1(0.0 \%$ vs. $\left.50.0 \%, \chi^{2}=6.67, p=0.010\right)$. However, at 6 month, the improvement in uroflowmetry was 


\section{JMSCR Vol||05||Issue||04||Page 20721-20730||April}

similar ( $>0.05)$ between the two groups though the normal flow was $10.0 \%$ higher in Group 2 than Group 1. No flow was present in group-1 at 6 weeks and voiding trial was failed.

Table 4: Post treatment distribution of uroflowmetry of two groups over the periods

\begin{tabular}{|l|c|c|c|c|c|}
\hline Period & Uroflowmetry & $\begin{array}{c}\text { Group 1 } \\
(\mathrm{n}=10)(\%)\end{array}$ & $\begin{array}{c}\text { Group 2 } \\
(\mathrm{n}=10)(\%)\end{array}$ & $\begin{array}{c}\chi^{2} \\
\text { value } \\
\text { value }\end{array}$ \\
\cline { 2 - 5 } & Abnormal flow & $10(100.0)$ & $5(50.0)$ & 6.67 & 0.010 \\
\hline 6 month & Normal flow & $0(0.0)$ & $5(50.0)$ & & \\
\cline { 2 - 5 } & Abnormal flow & $2(20.0)$ & $2(20.0)$ & & 0.49 \\
& Normal flow & $8(80.0)$ & $8(80.0)$ & & \\
\hline
\end{tabular}

\section{Secondary outcome measure}

\section{i. IIEF-5 score}

The IIEF-5 score of two groups at two different post periods ( 6 week and 6 month) is summarized in Table 5 and also depicted in Fig. 7. The mean
IIEF-5 score at both 6 week $(21.20 \pm 1.37$ vs. $22.50 \pm 1.37, \mathrm{p}=0.511)$ and 6 month $(22.00 \pm 1.36$ vs. $23.20 \pm 1.31, \mathrm{p}=0.533$ ) was higher in Group 2 than Group 1 but the difference was statistically insignificant i.e. did not differ significantly.

Table 5: Post treatment IIEF-5 score (Mean \pm SE, $n=10$ ) of two groups at two different periods

\begin{tabular}{|l|c|c|c|}
\hline Period & Group 1 & Group 2 & $\mathrm{p}$ value \\
\hline 6 week & $21.20 \pm 1.37$ & $22.50 \pm 1.37$ & 0.511 \\
\hline 6 month & $22.00 \pm 1.36$ & $23.20 \pm 1.31$ & 0.533 \\
\hline
\end{tabular}

\section{IIEF-5 scores}

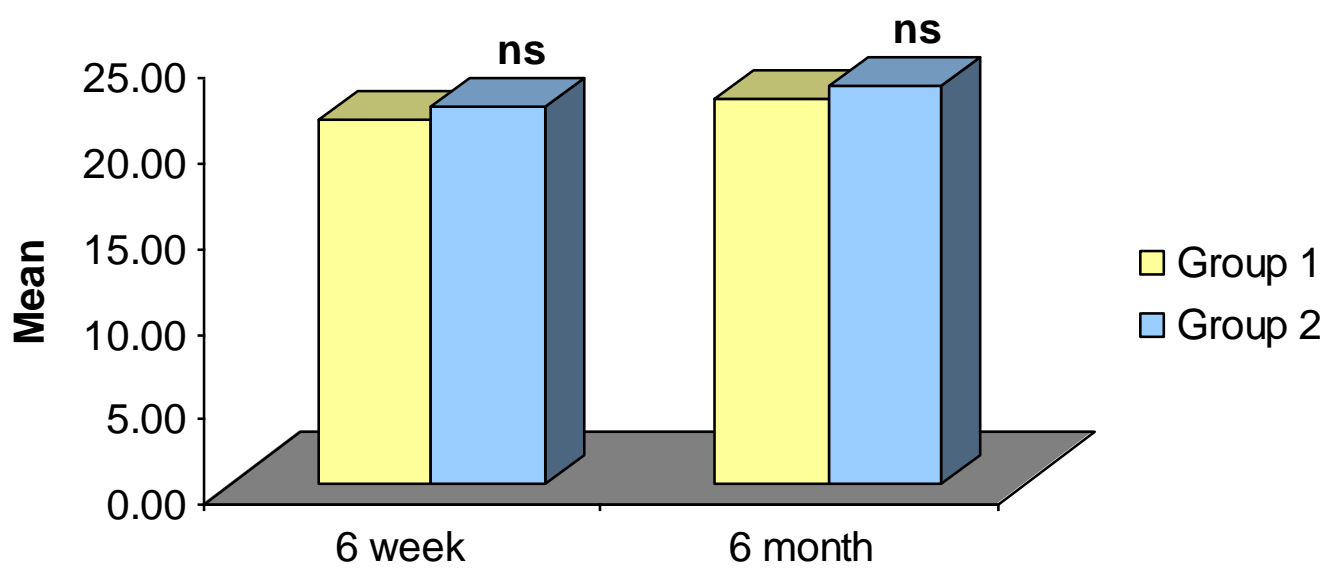

Fig. 7. Mean IIEF-5 score of two groups at two different periods.

\section{Penile color Doppler}

The penile color Doppler distribution (abnormal/ normal) of two groups at two different post periods (6 week and 6 month) is summarized in Table 8 and shown in Fig. 10. In both groups, the penile color Doppler distributions remain similar at both 6 wk and 6 month. Further, at both periods, the penile color Doppler frequency (\%) "normal" did not differ between the two groups $\left(70.0 \%\right.$ vs. $\left.80.0 \%, \chi^{2}=0.27, p=0.606\right)$ though it 
was $10.0 \%$ higher in Group 2 as compared to

Group 1 at both the periods.

Table 8: Post treatment penile color Doppler distribution of two groups at two different periods

\begin{tabular}{|l|c|c|c|c|c|}
\hline Period & Penile color Doppler & $\begin{array}{c}\text { Group 1 } \\
(\mathrm{n}=10)(\%)\end{array}$ & $\begin{array}{c}\text { Group 2 } \\
(\mathrm{n}=10)(\%)\end{array}$ & $\begin{array}{c}\chi^{2} \\
\text { value }\end{array}$ & $\begin{array}{c}\mathrm{p} \\
\text { value }\end{array}$ \\
\hline \multirow{2}{*}{6 week } & Abnormal & $3(30.0)$ & $2(20.0)$ & 0.27 & 0.606 \\
\cline { 2 - 4 } & Normal & $7(70.0)$ & $8(80.0)$ & & \\
\hline \multirow{2}{*}{6 month } & Abnormal & $3(30.0)$ & $2(20.0)$ & 0.27 & 0.606 \\
\cline { 2 - 4 } & Normal & $7(70.0)$ & $8(80.0)$ & & \\
\hline
\end{tabular}

\section{Penile color Doppler}

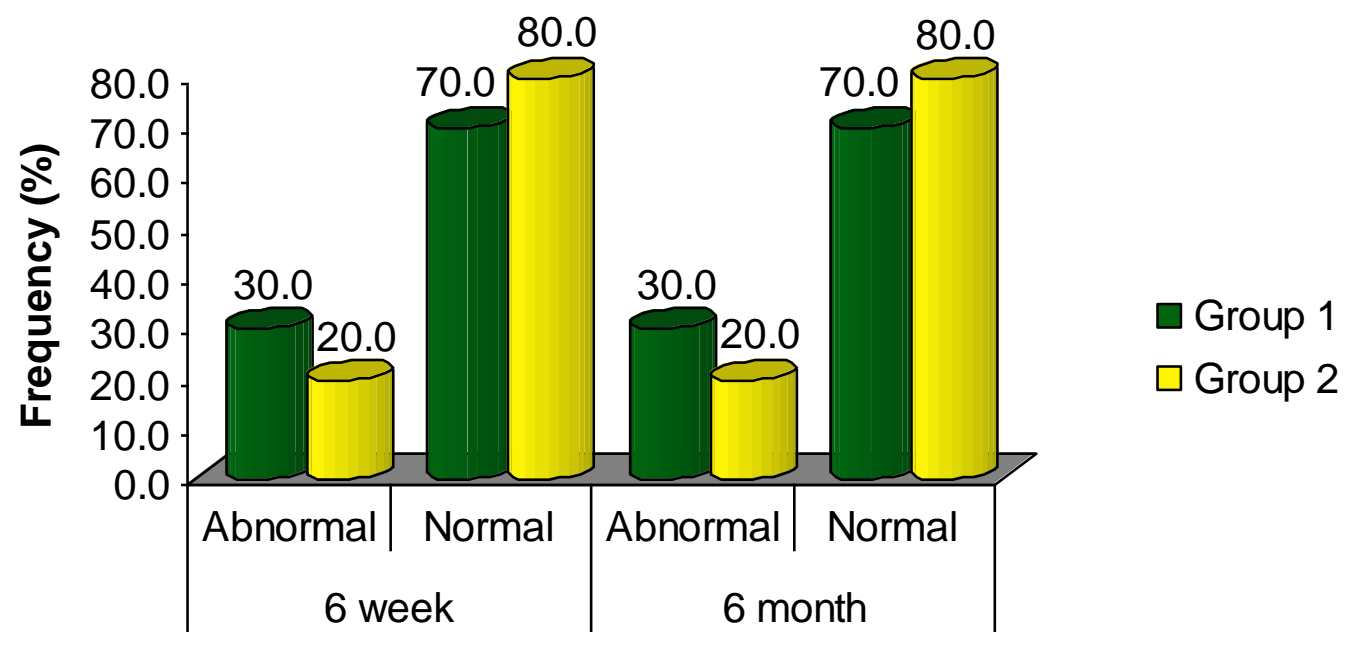

Fig. 10. Post treatment penile color Doppler distribution of two groups at two different periods

\section{Discussion}

Patients included in the study were all male patients between the age of 21-40 years. This age group (21-40 years) is the most productive age group, where in people enjoy taking risks, perform strenuous jobs and drive fast (Eustace and Wei, 2010; Gulliver and Begg, 2007) ${ }^{\mathrm{i}, \mathrm{ii}}$ just because of thrill or because of occupational compulsions (Jenkins et al., 1993; Leigh et al., 1993) ${ }^{11,12}$

In present study, major mode of injury was RTA. It was $70 \%$ in group- 1 and $80 \%$ in pts of group- 2 . Next to this mode of injury was fall from height and it was $20 \%$ in both groups. There was no significant difference in mode of injury between two groups. Stein et al. reported vehicular accidents as a cause for nearly $36 \%$ of urethral strictures in India, vs. $15 \%$ in a cohort from the USA and Italy

In our study PUC inserted by railroading method in $25 \%$ cases and $25 \%$ by endoscopic primary realignment. The selection of technique was done by simle randomization method.

We encountered good results using different techniques of management. Though complications such as stricture formation were encountered in group-1 and group-2, 100\%, and 50\% cases respectively at first follow up of $6^{\text {th }}$ weeks, requiring the additional procedure in patients of group-2. like urethral calibration, co-axial dilatation in $20 \%, 10 \%$ cases respectively and DVIU in 20\% cases. At 6 months follow up 30\% patients had no stricture with Qmax $>20 \mathrm{ml} / \mathrm{s}$ whereas $20 \%$ patients had recurrent stricture and required bulbo prostatic urethroplasty eventually. In group 1 patients were managed initially by suprapubic catheterization for urinary diversion followed by delayed urethroplasty. In this group $100 \%$ stricture formation was present in follow up after 6 wks which was evident by RGU and uroflowmetry studies. After 6months all the 
pateints had undergone urethroplasty and only $10 \%$ patients still had stricture urethra which warranted further surgical interventions like DVIU or Co-Axial di Manikandan, et al.: (Current concepts in themanagement of PFUDD distraction defects, 2011) The success rates of urethroplasty varied widely from $77 \%$ to $95 \%$ in various series, which was due to various definitions of surgical success. Restricture after anastomotic urethroplasty occurs in about $15 \%$ of cases. But most of these can be successfully corrected by 1 or 2 sessions of endoscopic internal urethrotomy.

In Group 2 patients were managed by primary realignment (open/endoscopic).In this group 50\% patients didn't have stricture urethra at 6 weeks follow up and were managed by self catheterization and CIC.30\% patients had partial urethral stricture at 6 weeks follow up and were managed by DVIU/Co-axial dilatation.

After 6 months follow up, only $20 \%$ patients had significant stricture urethra and required urethroplasty whereas $80 \%$ patients did not have any stricture on the RGU and normal Qmax and flow.

Koraitim, 2005 reviewed different techniques used in a personal series of 100 patients combined with a review of 771 patients from published reports. Immediate and early realignment was associated with rates of $53 \%$ for stricture, $5 \%$ for incontinence, and $36 \%$ for impotence. $42 \%$ needed subsequent instrumentation to attempt stabilization of stricture. Urethroplasty was ultimately necessary in $33 \%$. 16,17,18

In Group 1 the incidence of erectile dysfunction was 30\% whereas in Group 2 the incidence of erectile dysfunction was $20 \%$.

Anger et al,2009 37 men with current contact information available were contacted; 26 completed the IIEF questionnaire, including men who completed the questionnaires either at home or in the office, and men who were completed the IIEF over the telephone. The mean (range) patient age at the time of the interview was 40.2 (20-68) years and the mean time from the PFUDD repair to the interview was $4.4(1-14)$ years.
Overall, the mean IIEF score was 49.1 (10-73) of 75 possible points. Some degree of ED, as shown by scores on the EF domain, was present in 14 of 26 men (54\%). Fifteen men (58\%) had spontaneous EF, as shown by a

mean EF domain score of $>20$, and 11 men had a score of $\leq 20(42 \%)$. Eight men $(30 \%)$ met the criteria for severe ED. Five men of the eight who tried phosphodiesterase inhibitors responded well to them, and one had tried and responded to intracorporal injection therapy. One patient had a penile implant. Among the men with normal erections, one had previously had a successful penile revascularization procedure for a vascular injury at the time of his pelvic fracture.

Patwardhan et al, 2016 All patients with pelvis fracture urethral distraction defect (PFUDD) who required end-to-end urethroplasty (E-E urethroplasty) from August 2010 to July 2014 were included. Thirty-four per cent had defect length of $0.5-2 \mathrm{~cm}, 50 \%$ had defect length of 2.1$4 \mathrm{~cm}$. Of 32, 34\% required re-intervention. Inferior pubectomy was required in $36 \%$ in the $0.5-2 \mathrm{~cm}$ group and in $94 \%$ in the $2.1-4 \mathrm{~cm}$ group. On follow-up, $22 \%$ of patients had neurogenic $\mathrm{ED}$, and $63 \%$ had vascular $\mathrm{ED}$, of whom $44 \%$ had arterial, $3 \%$ had venous, and $16 \%$ had mixed aetiology. Patients with neurogenic aetiology had shorter urethral defect and $43 \%$ needed inferior pubectomy. Patients with vascular aetiology had longer urethral defect, $90 \%$ required inferior pubectomy.

In our study during the follow up of 2 weeks, 6 weeks and 6months in both Group 1 and Group 2, no incidence of Incontinence was found. It is probably associated with bladder neck injury but as these patients were not included in the present study therefore incidence of incontinence is zero.

In the stable patient with posterior urethral injury, primary urethral realignment, either surgical (with minimal paravesical dissection) or endoscopic, should be the treatment of choice since it results in a less than $50 \%$ incidence of stricture (most of which can be managed by minimally invasive techniques) and an acceptable rate of impotence 
and incontinence. This decrease in the need for surgery has a large positive impact because the perineal approach anastomotic urethroplasty can be lengthy and arduous for the surgeon and the patient. If patients are being explored for concomitant intra-abdominal, bladder neck or rectal injury, an attempt at immediate primary realignment using railroading techniques (without disturbance of the retropubic hematoma) should be made. If there are no indications for surgical exploration, endoscopic realignment should be attempted at any time from 1-15 days after the patient has stabilized. These techniques should not be performed by inexperienced surgeons or in centers where facilities for endoscopy/fluoroscopy are not available. In experienced hands, such an approach has been demonstrated to have better outcomes as compared to suprpubiccystosotmy alone

\section{Conclusion}

1) Major mode of injury was road traffic accidents (70\% in group 1 and $80 \%$ in group 2) followed by fall from height $(20 \%$ in group-1 and group- 2$)\left(\chi^{2}=1.07\right.$, $\mathrm{p}=0.587$ )

2) Patients in group-1 were followed by RGU at 6 weeks which showed $100 \%$ stricture formation with no flow on voiding trial and uroflowmetry at 6 weeks. At 6 months follow up patients had undergone urethroplasty and on RGU $80 \%$ patients had no stricture with Qmax>20ml/sec while $20 \%$ patients still had stricture on RGU and abnormal flow on uroflowmetry which required further interventions like DVIU/Co-axial dilatation.

3) Patients in group-2 were treated by early realignment (open/endoscopic).At 6 weeks follow up 50\% patients had no stricture on RGU and Qmax>20ml/s.50\% patients still had stricture formation. At 6 months follow up only $20 \%$ patients had stricture on RGU and Qmax<20ml/s and required bulbo prostati curethroplasty while $30 \%$ patients were treated by DVIU and CoAxial dilataion and had $\mathrm{Qmax}>20 \mathrm{ml} / \mathrm{s}$ and no stricture on RGU.

4) Erectile dysfunction was $20 \%$ in group 2 as compared to $30 \%$ in patients in group 1 with mean IIEF-5 score in group 1 at 6 weeks 21.20 and at 6 months 22.0 while in group 2 at 6 weeks 22.5 and at 6 months 23.20 .

5) Early realignment (open/endoscopic) seems to be the better option as it is associated with reduced stricture formation and the strictures formed are manageable by simpler techniques like DVIU/Co-axial dilatation and was also associated with reduced incidence of erectile dysfunction after follow up of 6 months. The study is ongoing and long term follow up is required to check the incidence of complications and treatment outcomes. But the procedure requires surgical expertise and equipment.

\section{References}

1. Levine JI, Crampton RS. Major abdominal injuries associated with pelvic fractures. Surg Gynecol Obstet. 1963; 116:223-6. [PubMed]

2. Wilkinson FO. Rupture of the posterior urethra with a review of twelve cases. Lancet.1961;1:1125-9. [PubMed]

3. Chapple C, Barbagli G, Jordan G, et al. Consensus statement on urethral trauma. BJU Int. 2004;93:1195-202

4. Cass AS, Godec CJ. Urethral injury due to external trauma. Urology. 1978;11:60711.[PubMed].

5. Eustace D, Wei H. The Role of Driver Age and Gender in Motor Vehicle Fatal Crashes. Journal of Transportation Safety and Journey. 2010; 2(1): 28-44.

6. Gulliver P, Begg D. Personality factors as predictors of persistent risky driving behavior and crash involvement among young adults. Injury Prevention 
2007;13:376-381.Jenkins EL, Kisner SM, Forsbroke DE, Layne LA, Stout NA, Castillo DN et al. Fatal injuries to workers in United States, 1980-1990: A decade of surveillance; national profile. Cincinnati, $\mathrm{OH}$, U.S. Department of Health and Human Services, CDC, NIOSH. DHHS (NIOSH) Publication No. 93-108, 1993

7. 'Dandan IS, Farhat W. Trauma, Lower genitourinary. http://emedicine.medscape.com/article/828251-overview.

8. Sandler CM, Goldman SM, Kawashima A. Lower urinary tract trauma. 8Davis K. Trauma to the Lower Abdomen. J. Nat. Med. Assoc. 1989; 82(10): 717-720.

9. Udeani J and Steinberg SR. Abdominal Trauma, Blunt. http://emedicine.medscape.com/article/433404-overview.

10. Sherry E. WorldOrtho Textbook of Orthopaedics, Trauma and Sports Medicine. Chapter 28., 2010.

11. Asci $\mathrm{R}$ et al. Voiding and Sexual Dysfunctions after Pelvic Fracture Urethral Injuries Treated with either Initial Cystostomy and Delayed Urethroplasty or Immediate Primary Urethral Realignment. Scandinavian Journal of Urology and Nephrology1999; 33(4): 228 - 233.

12. Z Shenfeld, D Kiselgorf, O N Gofrit, A G Verstandig, E H Landau, D Pode, Gerald H Jordan, Jack W McAninch The incidence and causes of erectile dysfunction after pelvic fractures associated with posterior urethral disruption. Department of Urology, Hebrew University Hadassah Medical Center, Jerusalem, Israel. Updates Surg. 2011 Sep ;63 (3):185-90 21739332

13. (Manikandan R, Dorairajan LN, Kumar S. Current concepts in the management of pelvic fracture urethral distraction defects. Indian J Urol 2011;27:385-91).

14. Venn SN, Mundy AR. Trauma and reconstruction. The immediate management of major trauma to the urinary tract. EurUrol 1998;33:1-8. 15
Martı'nez-Pin eiro JA, Carcamo P, Garc1'a Matres MJ, Martı'nez-Pin eiro L, Robles Iglesias J, Rodriguez Ledesma JM. Excision and anastomotic repair for urethral stricture disease: experience with 150 cases. EurUrol 1997;32:433-41.

15. Corriere JN. 1-Stage delayed bulboprostatic anastomotic repair of posterior urethral rupture: 60 patients with 1-year followup.JUrol 2001;165:404-7.

16. Muhlbauer S, Bard RH. Early definitive urologic management of patient with crush pelvic trauma and deep perineallaceration.Urology 1980;15:56-9.

17. Webster GD. Impotence following delayed repair of prostatomembranous urethral disruption (editorial comment). J Urol 1990;144:678

18. Fiala R, $\mathrm{Za}^{\prime}$ tura F, Vrtal R. [Personal experience with treatment of posttraumatic urethral distraction defects]. Acta Chir OrthopTraumatolCech 2001;68:99-104 [article in Czech].

19. Koraitim MM. The lessons of 145 posttraumatic posterior urethral strictures treated in 17 years. J Urol 1995;153:63-6.

20. Podesta ML. Use of the perineal and perineal-abdominal (transpubic) approach for delayed management of pelvic fracture urethral obliterative strictures in children: long-term outcome. J Urol 1998;160:1604.

21. (R. P. Shrinivas, Deepak Dubey. Primary urethral realignment should be the preferred option for the initial management of posterior urethral injuries.Indian J Urol. 2010 Apr-Jun; 26(2): 310-313)

22. Herschorn S, Thijssen A, Radomski SB. The value of immediate or early catheterization of the traumatized posterior urethra. J Urol 1992;148:1428-31.

23. Porter JR, Takayama TK, Defalco AJ. Traumatic posterior urethral injury and early realignment using magnetic urethral catheters. J Urol 1997;158:425-30. 
24. Guille F, Cipolla B, Leveque JM, Guirassy S, Olivo JF, Lobel B. Early endoscopic realignment of complete traumatic rupture of the posterior urethra.Br $\mathrm{J}$ Urol 1991;68:178-80.

25. Gelbard MK, Heyman AM, Weintraub P. A technique for immediate realignment and catheterization of the disrupted prostatomembranousurethra.JUrol 1989;142:52-5.

26. Ragde H, McInnes GF. Transpubic repair of the severed prostatomembranous urethra. J Urol 1969;101:335-7.

27. In Hyuck Gong, Jong Jin Oh, Don Kyung Choi, Jinho Hwang, Moon Hyung Kang, Young Tea Lee Department of Urology, CHA Bundang Hospital, CHA University College of Medicine, Seongnam, Korea. Comparison of Immediate Primary Repair and Delayed Urethroplasty in Men with Bulbous Urethral Disruption after BluntStraddle Injury. Korean J Urol 2012;53:569-572.

28. Corriere et al, 1994 ; Routt et al, 1996 ; Elliott and Barrett, 1997 ; Asci et al, 1999.
29. Follis et al, 1992 ; Herschorn et al, 1992 ; Elliott and Barrett, 1997 ; Porter et al, 1997 ; Corriere, 2001.

30. Mundy AR. Transperinealbulbo-prostatic anastomotic urethroplasty. World J Urol. 1998;16:164-70. Koraitim MM, Marzouk ME, Atta MA, et al. Risk

31. Factors and mechanism of urethral injury in pelvic fractures. Br J Urol 1996;71:87.

32. Lim PHC, Chung HC. Initial management of acute urethral injuries. $\mathrm{Br} \mathrm{J}$ Urol 1989;64:165-8.

33. Chapple C, Barbagli G, Jordan G, Mundy AR, Rodrigues-NettoN,Pansadoro V, et al. Consensus statement on urethral trauma. BJU Int 2004;93:1195-202.

34. Sherry E. WorldOrtho Textbook of Orthopaedics, Trauma and Sports Medicine. Chapter 28., 2010.).

35. Koraitim MM. Pelvic fracture urethral injuries: evaluation ofvarious methods of management. J Urol 1996;156:1288. 